\title{
miR-144 functions as an oncomiR in KYSE-410 human esophageal carcinoma cell line in vitro and targets PURA
}

\author{
P. SHARMA, R. SHARMA* \\ University School of Biotechnology, Guru Gobind Singh Indraprastha University, New Delhi-110078, India \\ *Correspondence: rinusharma@gmail.com
}

Received August 14, 2017/ Accepted November 3, 2017

\begin{abstract}
Esophageal cancer (EC) is a highly complex disease with high incidence and mortality rates. Recent studies have shown that miRNAs play critical roles in diverse biological processes including oncogenesis, and we previously reported significantly increased expression of tissue and circulating miR-144 in EC. This study evaluates the functional significance of miR-144 in esophageal squamous cell carcinoma. Herein, we analysed the role of miR-144 in ESCC by silencing it in KYSE-410 cells, and followed this with cell cycle analysis and the following assays; MTT, annexin, colony formation, scratch and matrigel invasion assay. The miR-144 knockdown significantly suppressed ESCC cell proliferation at 72 hours post transfection ( $\mathrm{p}=0.029)$. Silencing of miR-144 significantly decreased the migration, invasion and colony formation potential of KYSE- 410 cells compared to cells treated with negative control (NC). Potential targets of miR-144 were predicted by the in silico approach followed by in vitro validation in real time PCR and luciferase reporter assay. The PURA and Spred1 in silico predicted miR-144 targets were validated by qRT-PCR and luciferase reporter assay. Over-expression of miR-144 significantly decreased PURA mRNA expression by $58.85 \%$ at 24 hours post transfection $(\mathrm{p}=0.009)$. Further validation by dual-luciferase reporter assay confirmed it is a direct targets of miR-144. Our overall study suggests the oncogenic role of miR-144 in EC by promoting proliferation and migration of ESCC cells. To the best of our knowledge, this is the first report showing PURA as a direct miR-144 downstream target and suggests its potential as a novel therapeutic target for this disease.
\end{abstract}

Key words: esophageal cancer, ESCC, Spred1, PURA, cell proliferation, migration

Esophageal carcinoma (EC) is the eighth most common cancer worldwide, characterized by its high mortality rate and less than 25\% 5-year survival rate [1-2]. Aberrant expression of miRNAs has been implicated in various cancers and regulates key processes such as cell proliferation, apoptosis, metastasis and invasion by regulating gene expression of their tumor suppressor or oncogenic targets [2-3]. miR-144 is located on chromosome $17 \mathrm{q} 11.2$, a region reported to be amplified in both esophageal adenocarcinoma and nasopharyngeal carcinoma (NPC) [4-5]. While increased miR-144 expression has been reported in some cancers; including EC, NPC and gastric and rectal cancer [6-11] decreased expression was found in others [12-16]. One study showed that miR-144 inhibition reduced cell growth in HeLa cells [17], and others that miR-144 repression significantly decreased cell proliferation, clonogenicity, migration, invasion and tumor formation in nude mice and that restored miR-144 in miR-144 attenuated nasopharyngeal carcinoma cells had a strong tumorigenic role [8-9]. Interestingly, miR-144 was predicted to directly target caspase-3, and transfection of this miRNA two days before TRAIL treatment sufficiently reduced procaspase- 3 levels and affected activation of the caspase cascade [18]. PTEN is another bioinformatically predicted target of miR-144. This is a well-known tumor suppressor and is reportedly down-regulated in various cancers [19-21]. Notably, Zhang et al. (2013) demonstrated that miR-144 was significantly and inversely correlated with PTEN mRNA and protein level in clinical NPC specimens and cell lines. Subsequently, PTEN was confirmed to be the direct target of miR-144 by luciferase reporter assay, thus establishing its role in cell proliferation and migration. Moreover, miR-144 suppression resulted in reduced expression of pAKT and cyclin D1 and increased expression of E-cadherin, thereby establishing that miR-144 promotes proliferation, migration and invasion via PTEN/PI3K/Akt/ cyclin D1 or E-cadherin signaling pathway. Rb1 is a wellknown negative cell cycle regulator, and it was computationally determined the target of versican-bound miRNAs such as 
miR-144 [22-24]. In a recent study, transfection of versican 3'UTR arrested miRNA functioning which in turn relieved RB1, thus suggesting it is a potential miR-144 target [24].

Reported studies enable the inference that miR-144 functions as a tumor suppressor or as oncomiR in various cancers depending on tissue type. Although it is reportedly down-regulated in most expression analysis studies [12-16], functional analysis studies have revealed key tumor suppressors as targets of this miRNA, thus establishing its role as an oncomiR in cancer development and progression.

We previously reported significantly increased miR-144 expression in neoplastic and pre-neoplastic esophageal tissues and EC sera samples compared to the normal subjects [8], and also predicted potential miR-144 targets by DianamiRGen's four widely used target prediction programs (PicTar, miRanda, TargetScanS and DIANA-microT). The targets were further screened on gene ontology and hybridization minimum free energy; with PURA one of the most potential targets. Notably, PURA expression was found to be significantly and negatively correlated with that of miR-144 in $75 \%$ of EC tissues [8]. Therefore, we investigated if PURA was a direct downstream miR-144 target.

\section{Materials and methods}

Cell culture. Human esophageal squamous cell carcinoma (ESCC) cell line KYSE-410 was purchased from European Collection of Authenticated Cell Cultures (ECACC), supplied by Sigma-Aldrich, Bangalore, India. The cell culture was maintained in RPMI 1640 (Sigma Aldrich, Bangalore, India) supplemented with 10\% v/v FBS (Himedia, Mumbai, India), $100 \mathrm{U} / \mathrm{ml}$ penicillin and $100 \mu \mathrm{g} / \mathrm{ml}$ streptomycin (Himedia, Mumbai, India). HEK-293T cell line was purchased from NCCS Pune (India) and maintained in DMEM (Himedia, Mumbai, India) supplemented with 10\% FBS, $100 \mathrm{U} / \mathrm{ml}$ penicillin and $100 \mu \mathrm{g} / \mathrm{ml}$ streptomycin. The cell lines were maintained in a humidified incubator with $5 \% \mathrm{CO}_{2}$ and $95 \%$ humidity in $25 \mathrm{~cm}^{2}$ culture flasks at $37^{\circ} \mathrm{C}$. (Corning, NY, USA).

Transient transfection. KYSE-410 cells were cultured in $25 \mathrm{~cm}^{2}$ culture flask to approximately $80 \%$ density and collected by digestion and centrifugation, and then seeded in 96 well plates $\left(1.2 \times 10^{4}\right.$ cells/well $), 24$ well plate $\left(5 \times 10^{4}\right.$ cells/ well) or 6 well plate $\left(3 \times 10^{5}\right.$ cells/well). $100 \mathrm{nM}$ hsa-miR- 144 Inhibitor (Ambion, CA, USA) was transfected into the cells by Lipofectamine 3000 (Invitrogen, CA, USA) and Opti-MEM medium (Invitrogen, CA, USA) according to manufacturer instructions. mirVana miRNA Inhibitor Negative control \#1 (Ambion, CA, USA) was the negative control. For target identification experiments, miR-144 was over-expressed using $100 \mathrm{nM}$ miR-144 mimic (Ambion, CA, USA) and miRNA mimic Negative control \#1 was the negative control (Ambion, CA, USA).

Cells viability assay. KYSE- 410 cells were treated with $50 \mathrm{nM}$ and $100 \mathrm{nM}$ of miR-144 inhibitor and MTT assay was performed at 24, 48 and 72 hours post-transfection as previously described [25]. Briefly, $20 \mu \mathrm{l}$ MTT (Himedia, Mumbai, India) at $5 \mathrm{mg} / \mathrm{ml}$ concentration was added to $1.2 \times 10^{4}$ cells suspended in $200 \mu \mathrm{l}$ complete medium and incubated for 4 hours at $37^{\circ} \mathrm{C}$ in the dark. $100 \mu \mathrm{l}$ DMSO (Ameresco, Solon, $\mathrm{OH}, \mathrm{USA}$ ) was then added to each well and shaken for 20 minutes to dissolve crystals. Absorbance was measured at $570 \mathrm{~nm}$ by spectramax spectrophotometer (Molecular Devices, Sunnyvale, CA, USA). Percentage inhibition was calculated as: inhibition $(\%)=[(\mathrm{OD}$ value of the control group - OD value of experimental group)/OD value of control group] $\times 100 \%$.

Cell cycle analysis. Cell cycle analysis was performed by flow cytometry on FACS Calibur (BD Biosciences, CA, USA) as in [25]. Cells were fixed overnight in $70 \%$ ethanol at $-20^{\circ} \mathrm{C}$. To fix miRNA, inhibitor/NC treated and untreated cells were harvested and re-suspended in $300 \mu \mathrm{l}$ PBS and $700 \mu \mathrm{l}$ of chilled $100 \%$ ethanol was then added. After fixing, cells were stained with propidium iodide $(10 \mu \mathrm{g} / \mathrm{ml})$ and RNaseA $(100 \mu \mathrm{g} / \mathrm{ml})$. The stained cells were then subjected to flowcytometry and data was acquired. Analysis was performed by BD CellQuest ${ }^{\mathrm{Tn}}$.

Annexin assay. miR-144 inhibitor/NC was transfected and cell apoptosis was analysed $72 \mathrm{~h}$ post-transfection using Annexin-V-6) AAD Apoptosis Detection Kit I (BD PharMingen, Heidelberg, Germany) according to the manufacturer's instructions. Apoptosis was analyzed by flow cytometry (LSRII, Becton-Dickinson) using FACS diva version 6.1.3 (Becton Dickinson, Mountain View, CA, USA), and the cells undergoing early apoptosis were PE Annexin-V positive and 7-AAD negative.

Colony formation assay. KYSE-410 cells were transfected with $100 \mathrm{nM}$ miR-144 inhibitor or NC, and cells were trypsinized 24 hours post transfection and added to six well plate at $2 \times 10^{3}$ cells/well density. The plates were then incubated at $37^{\circ} \mathrm{C}$. After 7 days, the colonies were fixed with pre-chilled methanol and stained with Crystal Violet (Himedia, Mumbai, India). Images of stained tumor cell colonies were then recorded by digital camera and colonies containing at least 50 cells were quantified with imaging analysis tool Image J.

Wound healing assay. KYSE- 410 cells $\left(3 \times 10^{5}\right.$ cells/well) were seeded in a 6 -well plate overnight to obtain $90 \%$ confluency. Scratch assay was performed at 24 hours post-transfection with $100 \mathrm{nM}$ miR-144 inhibitor/NC as described in [25]. Briefly, a scratch was made through the center of each well using a $200 \mu \mathrm{l}$ pipette tip, thus creating an open "wound" that was clear of cells. The dislodged cells were removed by two washes with PBS, fresh media was added and plates were cultured. Images were taken at time 0 , immediately following the scratch and at 24,48 and 72 hours by $4 \times$ objective inverted microscope (Olympus, Tokyo, Japan). Migration to the open area was observed at 24, 48 and 72 hours post-scratching by ImageJ software. The percentage of wound closure was calculated as the percentage of wound area covered at a given time 
compared to the initial wound surface, so that wound closure $=$ (initial scratch width-final scratch width /initial scratch width) $\times 100$.

Transwell-Matrigel invasion assay. Transwell-Matrigel invasion assay was performed at 24, 48 and 72 hours after miR-144 knockdown, using Transwell inserts (Corning Inc.) coated with Matrigel (BD Biosciences) according to the manufacturer protocol. Transfected cells were harvested at 24,48 and 72 hours post-transfection and $5 \times 10^{4}$ cells suspended in PBS were seeded in the top chamber. RPMI medium containing 20\% FBS was added to the lower chamber as the chemo-attractant. Non-invasive cells on the upper surface of the membrane were removed by cotton swab after 24 hours incubation. The migrated or invaded cells on the lower surface of the membrane were fixed with chilled methanol, stained with DAPI and photographed in 5 randomly selected fields under at $10 \times$ magnification inverted microscope (Nikon, Tokyo, Japan). The cells were counted by Nikon imaging software NIS-Elements BR Ver4.40.00. Percentage cell invasion was calculated as the number of cells invading the matrigel coated transwell/number of cells migrated through uncoated transwell) $\times 100$.

miRNA extraction and quantitative RT-PCR. $3 \times 10^{5}$ cells were seeded in a six-well plate and $100 \mathrm{nM}$ of miR-144 mimic/ NC was transfected. The miR-144 expression of PURA and Spred 1 target cells was analyzed at 24 and 48 hours post transfection by qRT-PCR and total RNA was extracted by Trizol (Invitrogen, CA, USA). First strand cDNA synthesis was performed with universal cDNA synthesis kit (Exiqon A/S, Vedbaek, Denmark) according to the manufacturer protocol. The qRT-PCR of PURA and Spred1 was performed using gene specific primers as in Table 1 and Kapa SYBR fast real time PCR kit (Kapa Biosystems, Boston Wilmington, US).

A small RNA, 5S rRNA was the endogenous control for data normalization (Table 1), and the $2^{-\Delta \Delta C T}$ method calculated fold change where, $\Delta \mathrm{Ct}=\mathrm{Ct}($ target gene $)-\mathrm{Ct}(5 \mathrm{~s})$, $\Delta \Delta \mathrm{Ct}=\Delta \mathrm{Ct}(\mathrm{miR}-144$ treated $)-\Delta \mathrm{Ct}$ (scrambled or untreated).

PURA-3'UTR pMIR-REPORT construct. A $757 \mathrm{bp}$ region from the $3^{\prime}$-UTR at position 1030-1786 of the PURA

Table 1. Primers used for qRT-PCR.

\begin{tabular}{llcc}
\hline $\begin{array}{l}\text { Gene } \\
\text { Name }\end{array}$ & Sequence & $\begin{array}{c}\text { Length } \\
\text { (bp) }\end{array}$ & Tm \\
\hline Spred1 & Forward: 5'-GAGACAGTTGTTACCAGTGAGCC-3' & 132 & F: 58.77 \\
& Reverse: 5'-TGTCCAAGCCTGGCTGACCAAA-3' & & R: 67.84 \\
\multirow{2}{*}{ PURA } & Forward: 5'-CACCTCCTTGACTGTGGACAAC-3' & 153 & F: 60.42 \\
& Reverse: 5'-GCAGAAGGTGTGTCCGAACTTG-3' & & R: 62.82 \\
& Forward: 5'-GTCTACGGCCATACCACCCTG-3' & & F: 59.77 \\
5S & Reverse: 5'-AAAGCCTACAGCACCCGGTAT-3' & 121 & R: 65.84 \\
\hline
\end{tabular}

Table 2. Primer used for PCR amplification of PURA 3'UTR (757 bp).

Primer Sequence Position

Forward 5'-GCCACGCGTCAAACTGAATGAAACCCCCACA-3' 1030-1051

Reverse 5'-CGCAAGCTTAGTTTAAGGTCCAGATGCAATG -3' 1765-1786
mRNA sequence (NM_005859) containing two potential miR-144 binding sites was amplified. The luciferase reporter gene construct was created by cloning this amplified fragment between the Mlu1 and HINDIII restriction sites in the pMIR-REPORT luciferase vector with the primers described in Table 2 (Promega, Madison, WI).

Luciferase reporter assay. HEK-293T cells at $10^{5}$ cells/ well were seeded in a 24-well plate and incubated overnight. The cells were then co-transfected with 100ng PURA-3'UTR pMIR-REPORT construct, 10ng Renilla luciferase vector and either $100 \mathrm{nM}$ miR-144 mimic or NC using Lipofectamine 3000 (Invitrogen). The relative firefly luciferase activity, normalized with Renilla luciferase, was determined by the dual-luciferase reporter gene assay system (Promega, Madison, WI, USA) and the results were plotted as percentage change over the respective control.

Statistical analysis. The Student t-test analyzed the statistical significance between the two groups and one-way ANOVA determined the significance of differences in multiple groups, $\mathrm{p}<0.05$ was statistically significant, and when this occurred multiple comparisons were performed between treatments in each time period by Tukey HSD test. All statistical analyses were performed by GraphPad PRISM software version 6.00 (San Diego, CA) and SPSS software 16.0 (SPSS Inc, Chicago, IL, USA).

\section{Results}

Knockdown of miR-144 suppressed cell proliferation of esophageal cancer cells. miR-144 knockdown decreased cell proliferation in time and dose dependent manner (Figures 1A,B). KYSE-410 cells transfected with $100 \mathrm{nM}$ miR-144 inhibitor had significantly lower viability with inhibition rate of $42.085 \pm 1.73 \%$ than those transfected with negative control 72 hours post transfection $((\mathrm{p}=0.029$ - inhibition rate $19.50 \pm 5.4 \%)$. Tukey's multiple comparison test revealed no significant difference at 24 or 48 hours after transfection ( $p>0.05$, Figure 1B). The cell proliferation was also significantly inhibited in cells treated with $50 \mathrm{nM}$ miR-144 inhibitor $(\mathrm{p}=0.017$ - inhibition rate $35.511 \pm 1.29 \%)$ compared to the NC (Inhibition rate $19.92 \pm 1.49 \%$ ) at 72 hours post transfection (Figure 1A).

Effect of miR-144 knockdown on ESCC cell cycle. Cell population in the G1 phase increased from $72.44 \pm 3.14 \%$ at 72 hours post-transfection (in NC treated cells) to $73.86 \pm 2.43 \%$ in $100 \mathrm{nM}$ miR-144 inhibitor treated cells. Small and non-significant decreases were observed in the G2/M phase population (from $11.52 \pm 2.7 \%$ to $10.62 \pm 1.99 \%$ ) and in the $S$ phase $(13.22 \pm 0.96 \%$ to $12.6 \pm 0.596 \%)$ (Figures $2 \mathrm{~A}, \mathrm{~B}, \mathrm{D})$. At 48 hours post-transfection, the cells in $\mathrm{S}$ phase decreased from $9.7 \pm 2.6 \%$ (NC) to $8.5 \pm 1.8 \%$ (Inhibitor) while cells in $\mathrm{G} 2 / \mathrm{M}$ phase increased from $18.55 \pm 0.75 \%$ (in NC) to $19.65 \pm 0.75 \%$ in miR-144 inhibitor transfected group. No difference was determined in the G0/G1 phase (Figure 2C). 

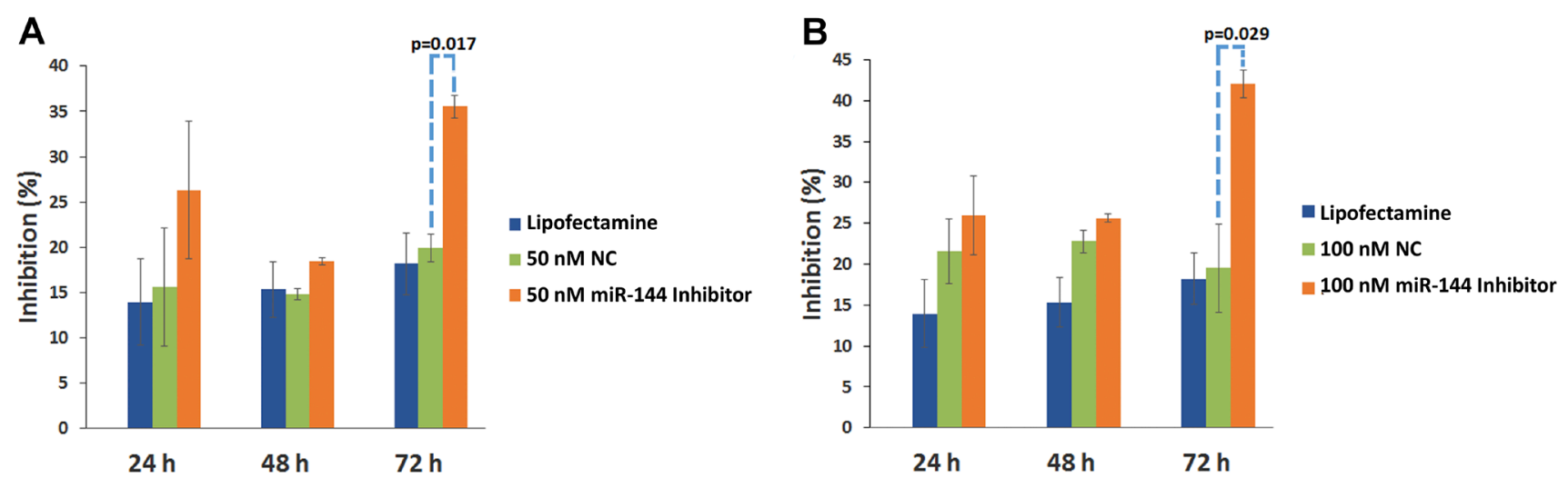

Figure 1. Histogram representing the percentage inhibition in cell proliferation after transfection of A) $50 \mathrm{nM}$ miR-144 inhibitor and B) $100 \mathrm{nM}$ miR144 inhibitor at $24 \mathrm{~h}, 48 \mathrm{~h}$ and $72 \mathrm{~h}$.

A

Negative Control

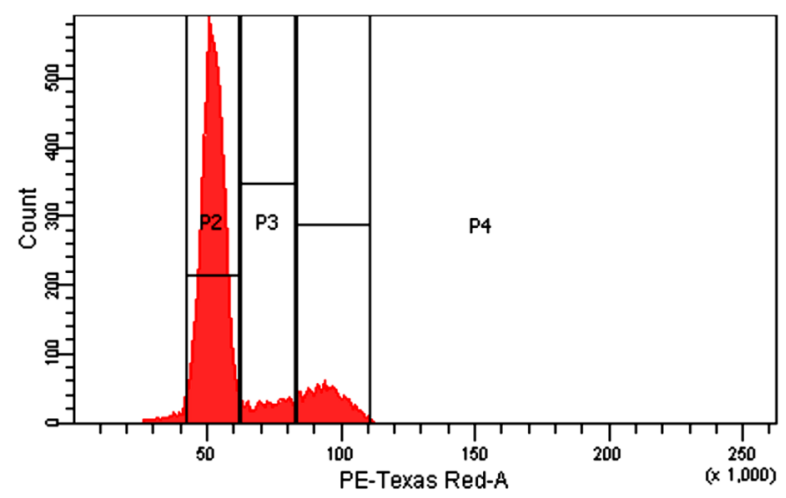

C

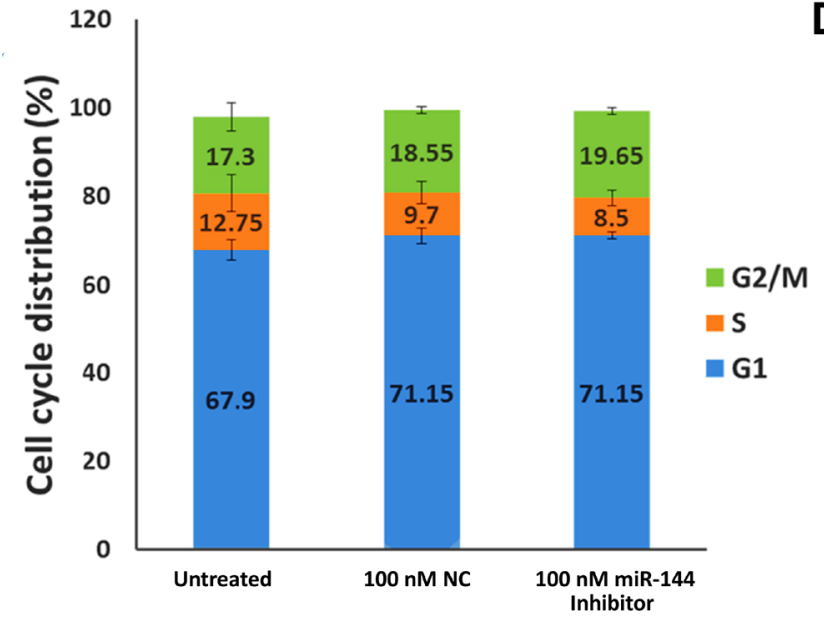

B

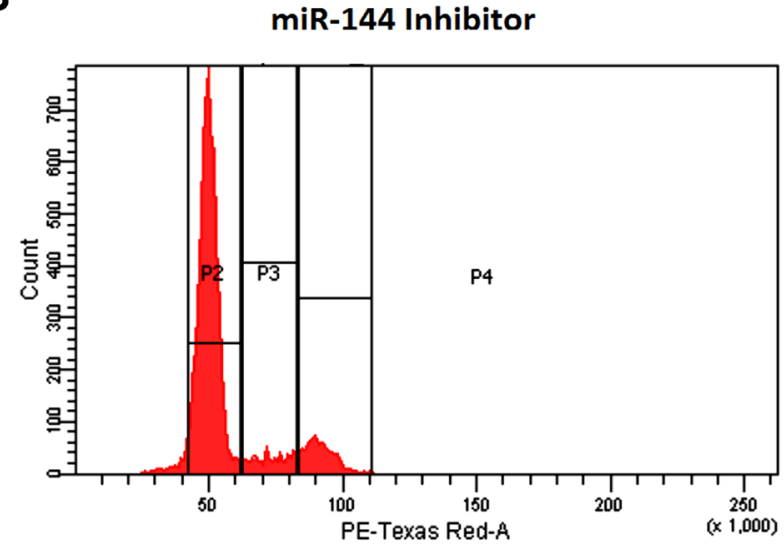

D

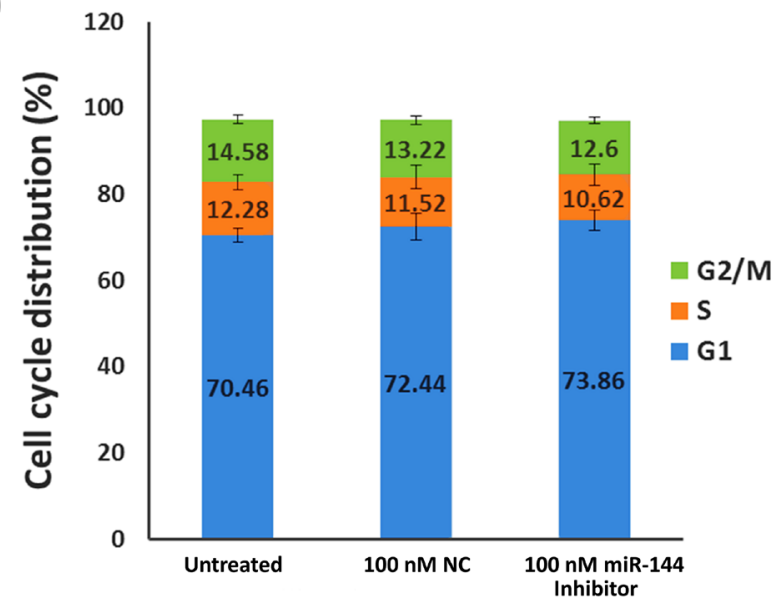

Figure 2. Flow cytometry results showing A) Effect of miR-144 knockdown on cell cycle of KYSE-410 cells as compared to B) NC and C) Histograms showing cell cycle distribution in miR-144 inhibitor/NC/Untreated ESCC cells at 48 h post-miR-144 knockdown D) Histograms showing cell cycle distribution in miR-144 inhibitor/NC/Untreated ESCC cells at $72 \mathrm{~h}$ post-miR-144 knockdown.

miR-144 effect on ESCC cell apoptosis. Flow cytometry based PE Annexin V apoptosis assay showed the percentage of early apoptotic cells at 72 hours post miR-144 knockdown increased to $35.05 \pm 2.75 \%$ compared to the negative control
$(31.35 \pm 3.95 \%)$, but this was not statistically significant (Figure 3).

miR-144 knockdown effect on ESCC cell colony formation potential. Clonogenic assay evaluated the ability of 
a single cell to proliferate into a colony. Significantly fewer colonies were observed after miR-144 inhibitor transfection (244.75 \pm 25.1$)$ compared to NC $(353 \pm 10.1)$ and untreated cells ( $570.5 \pm 37.28$, Figure 4$)$. When normalized to untreated cells, miR-144 inhibitor treated cell colony formation efficiency was significantly reduced at $\mathrm{p}<0.001$ to $42.91 \pm 3.54 \%$ compared to the NC treated cells' $62.04 \pm 3.81 \%$ (Figure 4).

miR-144 knockdown suppressed ESCC cell wound healing. Scratch assay detected miR-144 knockdown effect on KYSE-410 cell migration. Wound closure was evaluated at 24,48 and 72 hours post-scratching, and this established that 72 hours were required for untreated cell to complete wound closure. Wound-healing assay demonstrated that cell migration was significantly decreased in cells transfected with the miR-144 inhibitor compared to the negative control.
The maximum miR-144 knockdown effect on KYSE-410 cell migration potential occurred at 48 hours post scratching $(\mathrm{p}=0.039$, Figure 5$)$. The migration potential decreased by $20.34 \%$ with wound closure percentage of $67.49 \%$ in miR-144 inhibitor treated group compared to the NC $87.84 \%$. At 24 hours post scratching, miR-144 knockdown significantly blocked KYSE- 410 cell migration potential at $\mathrm{p}=0.017$ compared to negative controls. Wound closure percentage was $30.83 \%$ in the miR-144 inhibitor compared to $47.77 \%$ in NC treated cells. Significant difference in KYSE-410 cell migration potential was also established at 72 hours post scratching, with $86.95 \%$ closure percentage compared to $99.28 \%$ in $\mathrm{NC}(\mathrm{p}=0.013$, Figure 5$)$.

miR-144 knockdown effect on migration and ESCC cells invasion potential. Evaluation of the miR-144 knockdown effect on KYSE-410 cell migration and invasion potential
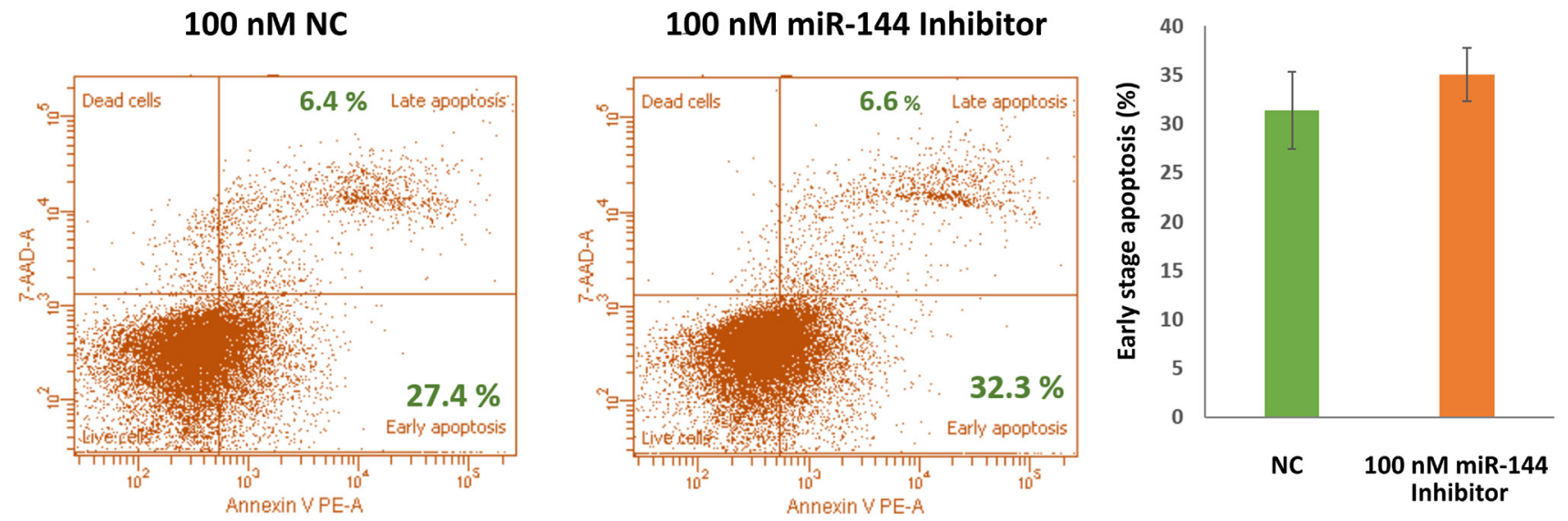

Figure 3. Effect of miR-144 knockdown on apoptosis of ESCC cells. Flow cytometry results showing percentage of early and late apoptosis in cells transfected with A) $100 \mathrm{nM} \mathrm{NC}$ and B) $100 \mathrm{nM}$ miR-144 inhibitor at $72 \mathrm{~h}$ post-transfection. C) Histogram showing percentage of cells undergoing early apoptosis in $\mathrm{NC}$ and miR-144 inhibitor transfected groups at $72 \mathrm{~h}$ post-transfection.

A

Untreated

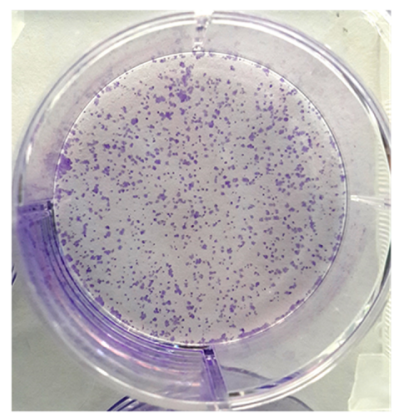

$100 \mathrm{nM}$ NC

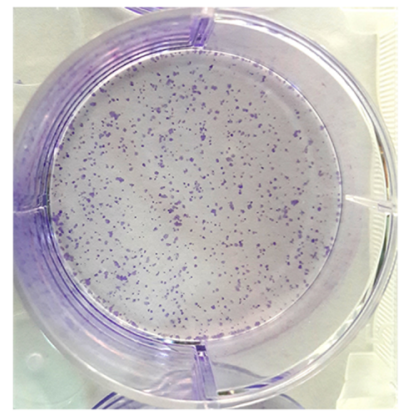

$100 \mathrm{nM}$ mimic

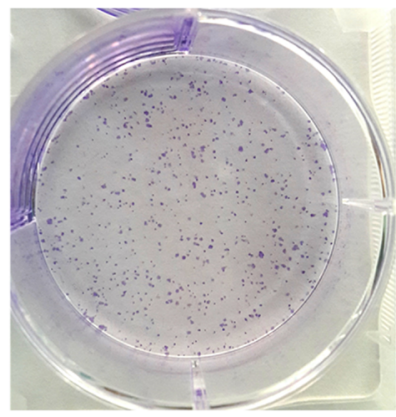

B

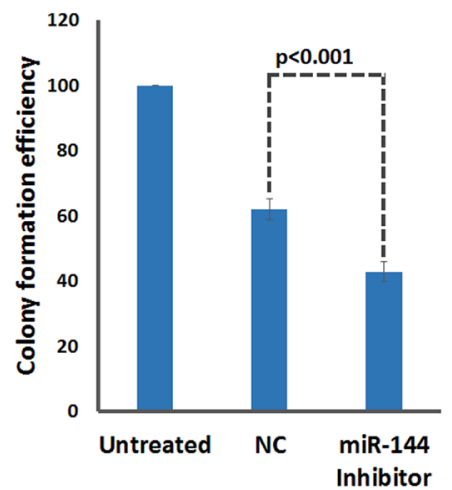

Figure 4. Effect of miR-144 knockdown on colony formation potential of ESCC cells. A) Representative images of colony formation assay after transfection of miR-144 inhibitor or NC for seven days. B) Histogram showing relative colony formation efficiency in miR-144 inhibitor or NC treated group when normalized to untreated group. 
A
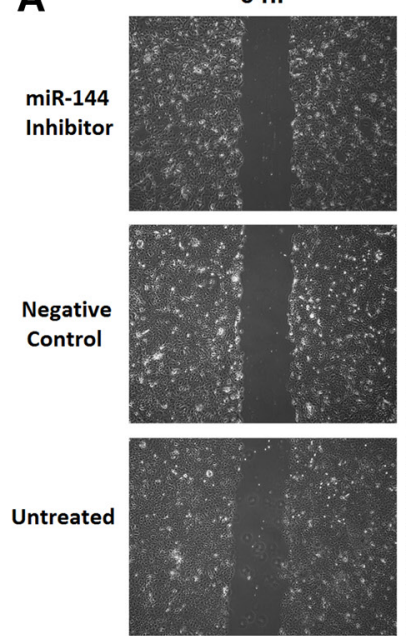

$24 \mathrm{~h}$
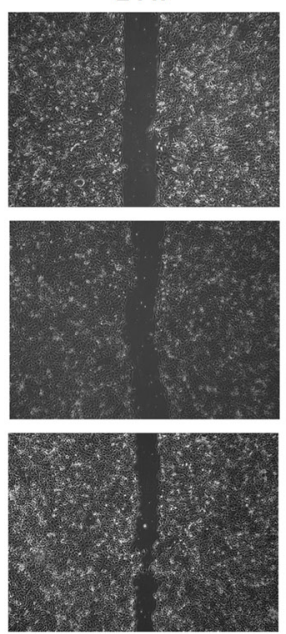

$48 \mathrm{~h}$
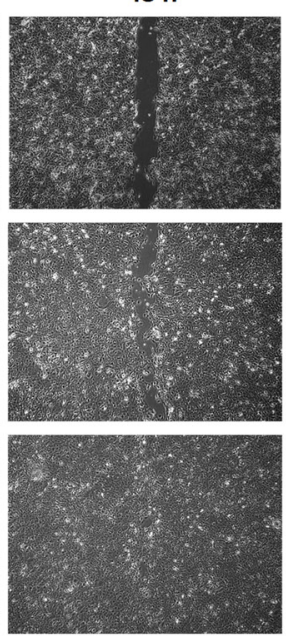

$72 \mathrm{~h}$
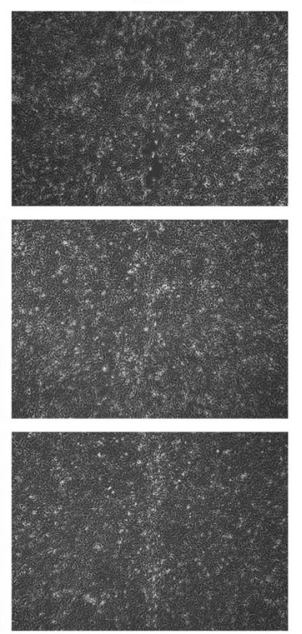

B

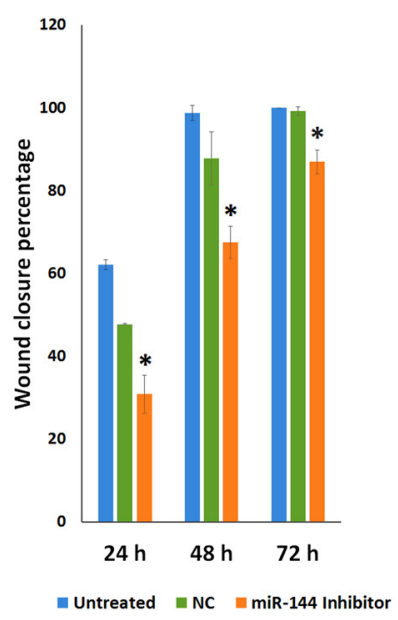

Figure 5. Knockdown of miR-144 inhibited wound healing of KYSE-410 cells. A) Representative images of wound healing assay at $24 \mathrm{~h}$, $48 \mathrm{~h}$ and $72 \mathrm{~h}$ post-scratching in miR-144 inhibitor/NC transfected and untreated cells. B) Histogram showing wound closure percentage in miR-144 inhibitor/NC treated and untreated groups.

A
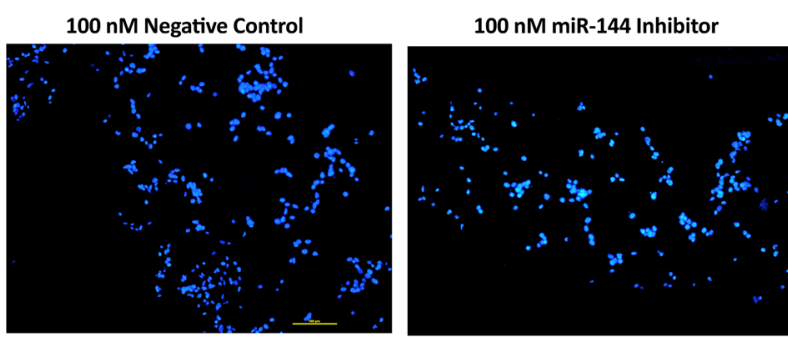

B
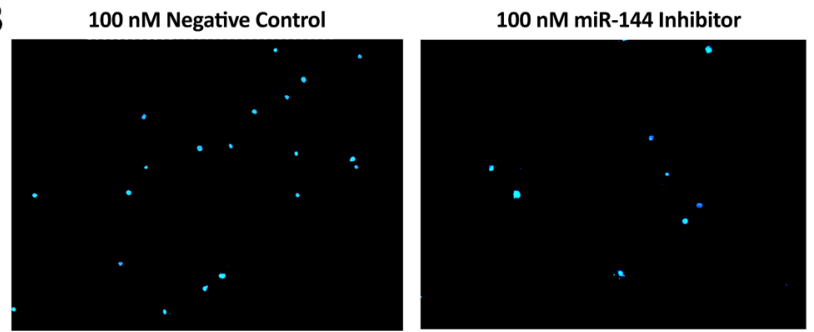

C

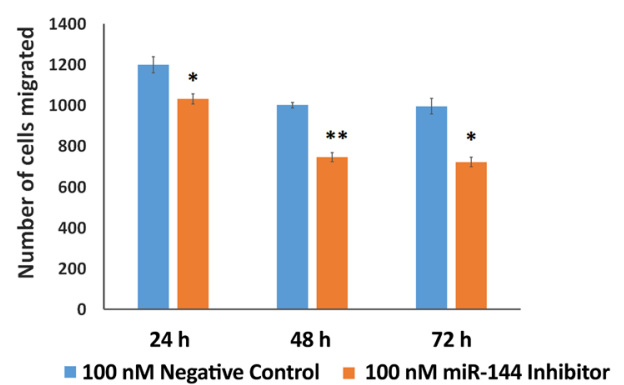

D

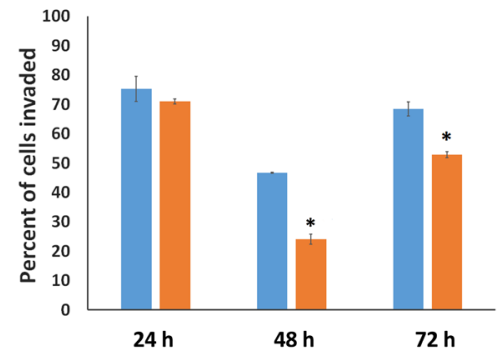

$\approx 100 \mathrm{nM}$ Negative Control $\quad 100 \mathrm{nM}$ miR-144 Inhibitor

Figure 6. Effect of miR-144 knockdown on the migration and invasion potential of ESCC cells. A) Representative images of transwell migration assay showing the number of cells migrated in the miR-144 inhibitor or negative (NC) transfected group at $48 \mathrm{~h}$ post transfection. B) Representative images of transwell-matrigel invasion assay showing the KYSE-410 cells invaded in the miR-144 inhibitor or NC-transfected groups at $48 \mathrm{~h}$ post transfection. C) Histogram showing the number of cells migrated through the chamber in the $100 \mathrm{nM}$ miR-144 inhibitor or NC treated groups at $24 \mathrm{~h}, 48 \mathrm{~h}$ and 72 $h$ post transfection. D) Histogram showing the percent of cells invaded through the matrigel in the $100 \mathrm{nM}$ miR-144 inhibitor or NC treated groups at $24 \mathrm{~h}, 48 \mathrm{~h}$ and $72 \mathrm{~h}$ post transfection.

with Transwell assay confirmed our findings. Here, miR-144 knockdown resulted in significantly decreased KYSE-410 cell migratory ability at all the time limits. However, the most significant decrease was observed at $48 \mathrm{~h}$ post transfection ( $\mathrm{p}=0.009$, Figure 6); 746 $\pm 22 \mathrm{miR}-144$ inhibitor transfected KYSE-410 cells migrated through the chamber compared to $1002 \pm 14$ in the NC transfected group, (Figures 6A,C). Notably, KYSE-410 cell invasive ability significantly decreased by $22.58 \pm 1.87$ percent after mir-144 knockdown compared to the NC group ( $\mathrm{p}=0.034$, Figures $6 \mathrm{~B}, \mathrm{D}$ ). Here, the number of NC-treated group invasive cells was $467 \pm 8$ compared to $179 \pm 8$ cells in the inhibitor treated group. Out of all the migrated cells $46.65 \pm 0.12 \%$ of all cells in the NC treated group were invasive compared to only $24.07 \pm 1.74 \%$ in the inhibitor treated group, and this suggests relatively weaker KYSE- 410 cell invasive ability after miR-144 knockdown (Figure 6D). 
miR-144 over-expression resulted in decreased expression of PURA at mRNA level. Interestingly, over-expression of miR-144 significantly decreased PURA mRNA expression by $58.85 \%$ at 24 hours post transfection $(\mathrm{p}=0.009)$ and fold change in miR-144 treated cells was $0.411 \pm 0.057$ compared to NC treated cells (Figure 7A). After 48 hours, PURA mRNA decreased to $0.732 \pm 0.001$ folds in mimic treated cells compared to the NC ( $p=0.001$, Figure $7 \mathrm{~B})$. This suggests that miR-144 regulates PURA expression at the transcriptional level more effectively at 24 hours post transfection than at 48 hours, but further validation at the protein level is warranted. While over-expression of miR-144 resulted in substantially decreased Spred1 expression at the mRNA level in mimic treated cells (fold change $=0.54 \pm 0.195$ at $24 \mathrm{~h}$ ) compared to the NC group (Figure 7C), this was not statistically significant. However, no decrease was observed in the mimic treated group Spred 1 mRNA expression 48 hours post transfection compared to NC's (Figure 7D).

miR-144 directly targets PURA 3'UTR. Bioinformatic analysis revealed two miR-144 target sites located in PURA mRNA 3'-UTR. These were site1 at position 1088 and site 2 at position 1600, and the predicted minimum free energy of hybridization (MFE) for the binding of these two sites were $-18 \mathrm{Kcal} / \mathrm{mol}$ and $-17.5 \mathrm{Kcal} / \mathrm{mol}$ respectively. When comparing the human sequence for interspecies homology, we found that, site1 was conserved across species such as mouse, rat and dog compared to site 2 (Figure 8A).

Dual luciferase reporter assay with constructs containing predicted PURA target binding sites assesses if miR-144 directly interacts with these targeting sites. When cells were transfected with miR-144 24 hours post transfection, the target site activity was significantly reduced by $26.98 \pm 0.02 \%$ compared to cells transfected with the negative control $(\mathrm{p}=0.015$, Figure $8 \mathrm{~B})$.
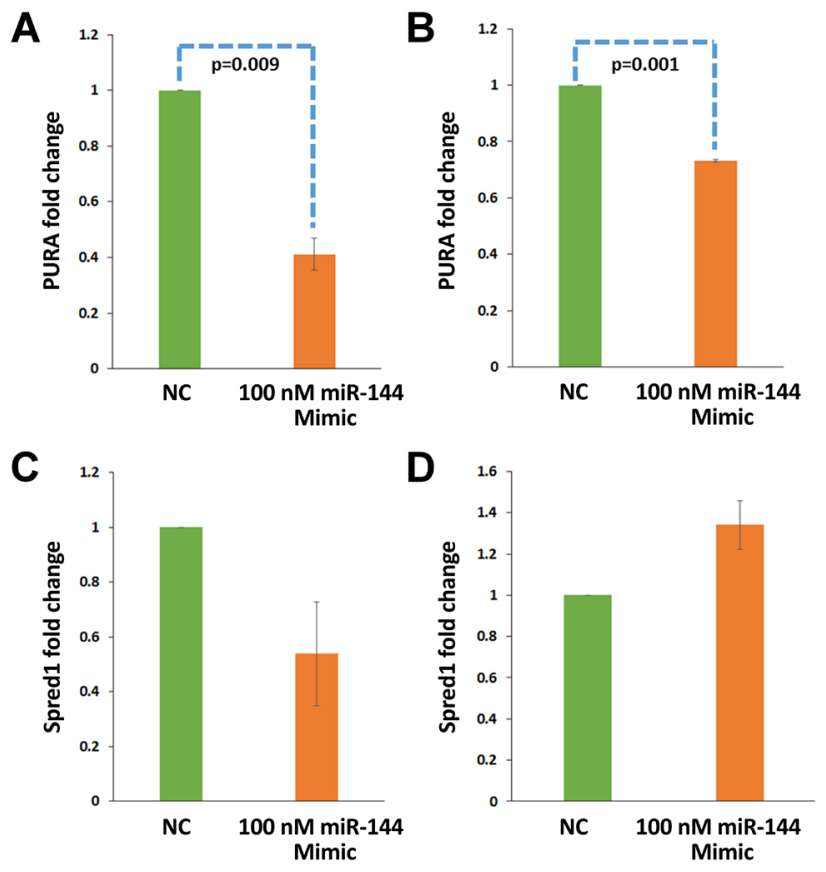

Figure 7. miR-144 overexpression resulted in decreased expression of its target mRNAs: Histogram showing fold change in expression of A) PURA mRNA at $24 \mathrm{~h}$ and $\mathrm{B}) 48 \mathrm{~h}$ post miR-144 transfection as compared to the NC C) Histogram showing fold change in expression of Spred1 mRNA at 24h and D) $48 \mathrm{~h}$ post miR-144 transfection as compared to the NC.
A

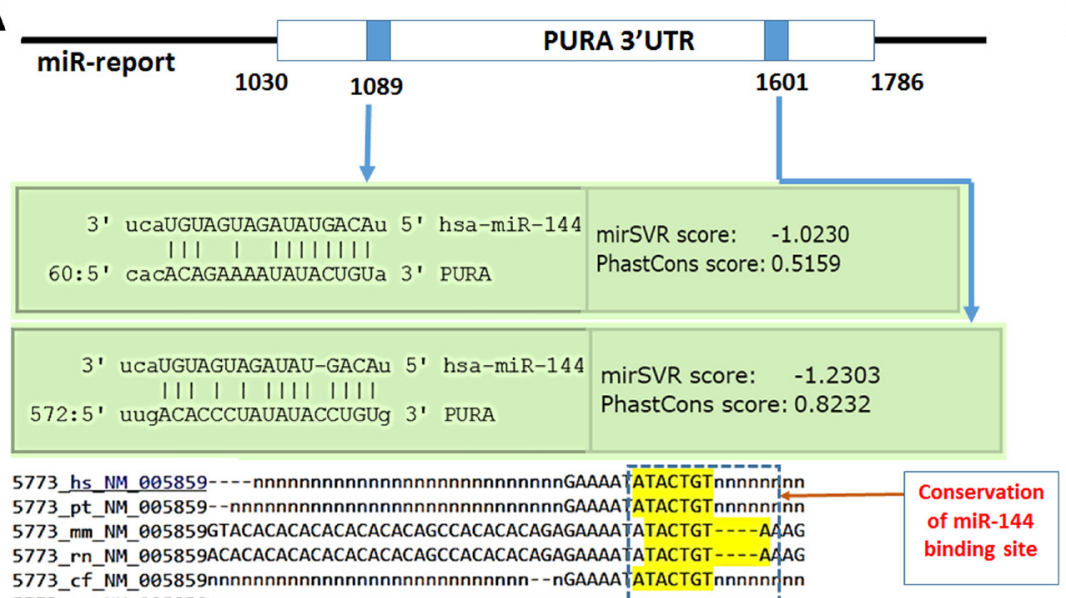

5773_cf_NM_005859nnnnnnnnnnnnnnnnnnnnnnnnnnnn--nGAAAATATACTGTnnnnnrnn

5773_gg_NM_065859-_-_._-

r_NM_005859-

100
110
120
13
B

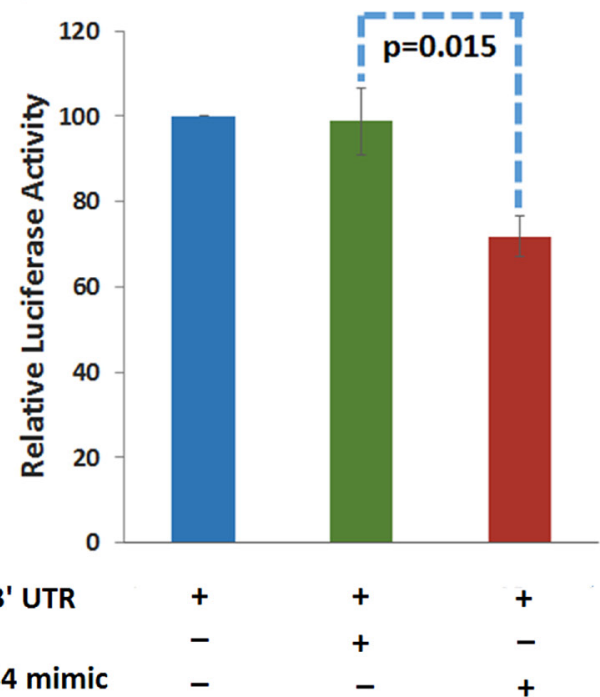

Figure 8. PURA is a direct target of miR-144. A) Figure showing potential binding site of miR-144 in PURA 3'UTR. PicTar revealed conservation of miR-144 binding site B) Relative luciferase activity in cells co-transfected with miR-144 mimic and PURA 3'-UTR in HEK293T cell line as compared to NC at 24 h post transfection. UTR, untranslated region; NC, Negative Control. 


\section{Discussion}

Precise knowledge of the molecular mechanisms involved in esophageal carcinogenesis and its progression is imperative for effective management of this disease. Herein, we unraveled the oncogenic function of miR-144 in esophageal carcinogenesis and further validated PURA as one of its newly identified targets.

In our previous study, we found marked miR-144 up-regulation in EC tissues compared to distant matched non-malignant tissues [8], thus agreeing with Xie et al. (2013) who demonstrated significant salivary up-regulation in EC patients [9].

Moreover, a recent report by Manikandan et al. (2016) established increased miR-144 expression in oral squamous cell carcinoma [26]. RT-PCR validation and bioinformatics analysis showed up-regulation of miR-144 in lung cancer metastasis [27]. In addition, it was also associated with overall survival in gastric cancer [10]. Notably, overexpression of miR-144 activated AKT by down-regulating PTEN in breast cancer cells and NPC $[6,28]$. In addition, it inhibited E-cadherin expression and promoted snail expression. Other experimentally validated miRNA-144 targets include RB1 and NOTCH1 [24, 29].

While our results agree with studies which suggest similar miR-144 function in EC. However, they differ to studies where 144 up-regulation suppresses cell proliferation, migration and increased apoptosis [30-34]. Overall miR-144 expression results indicate that miR-144 biology is cell-type dependent and further investigation will precisely determine its role in EC.

We then analyzed the effect of miR-144 silencing on EC cell proliferation to elucidate its role in EC tumorigenesis. Resultant miR-144 knockdown significantly lowered ESCC cell viability compared to negative controls and a significant decrease in KYSE-410 colony formation was noted after treatment with miR-144 inhibitor. Further, our observed miR-144 proliferative role is consistent with previous findings where its inhibition decreased HeLa cell growth and over-expression increased breast cancer cell proliferation [28]. miR-144 knockdown also inhibited cell proliferation, decreased foci formation and inhibited tumorigenesis in nude mice [6] and its transfection two days prior to TRAIL treatment sufficiently depleted the levels of procaspase- 3 to adversely affect the caspase cascade [18].

In further investigation, flow-cytometric annexin assay revealed a small increase in early stage apoptosis in miR-144 inhibitor treated cells compared to NC, thus suggesting anti-apoptotic potential in esophageal carcinogenesis. miR-144 knockdown also significantly blocked KYSE-410 cell migratory and invasive abilities compared to the control cells.

Reports that miR-144 promotes migration and invasion of breast cancer cells [28], and that its knockdown suppressed cell mobility and invasion in nude mice [6] support the proliferative and oncogenic role of miR-144 in esophageal carcinogenesis.

Cancer cells have voracious need for transcriptional and translational processes to ensure abundance of gene products required for cell proliferation and metastasis. It therefore favors oncogenic transcription factors and inhibits cell cycle regulators; and this consequently tends to favor PURA protein ability to bind and form complexes with transcription factors and other regulatory proteins required for cell proliferation including retinoblastoma protein $(\mathrm{pRb})$, E2F-1, cyclin T1/Cdk9 and cyclin A/Cdk2 etc [35-38].

Genome-wide micro-array analysis established PURA as a cancer associated gene present at deleted loci with decreased expression in human pro-myelocytic leukemia cells [39]. It is significantly down-regulated in chronic myeloid leukemia [40] and repressed at both protein and mRNA levels in androgen-independent prostate cancer cells [41] Further, ectopic PURA over-expression has suppressed proliferation of a variety of tumor cells including human glioblastoma [42] and Stacey et al. (1999) showed that high levels of PURA blocked the cell cycle at specific points in the cell cycle G2 phase and with less efficiency in the G1 phase [43]. Collectively, these findings indicate a regulatory role of PURA in cell proliferation, cell cycle progression and tumorigenesis.

Our previous PCR analysis showed a significant and negative correlation between miR-144 expression and PURA mRNA levels. In contrast to the increased expression of miR-144, PURA was expressed at lower levels in human EC tissues compared to matched distant non-malignant tissues [8]. Therefore, we further analysed the expression of PURA mRNA in cells treated with miR-144 mimic. Interestingly there was a significant decrease in expression of PURA mRNA at 24 and 48 hours post transfection. Further validation by luciferase reporter assay confirmed PURA as a direct downstream target of miR-144. These combined results strongly suggest that decreased PURA expression plays an important role in the progression of a wide array of cancers. Herein, we identified PURA as a novel direct target of miR-144 and established that the PURA down-regulation in EC is most likely due to increased miR-144 expression.

The Sprouty-related Ena/VASP homology 1-domaincontaining protein-1, Spred1, is the other predicted target of miR-144. Spred 1 is a well-known suppressor of Ras/Raf/ERK signalling [44], and while miR-144 over-expression resulted in marked decrease in Spred1 expression at the mRNA level 24 hours post transfection in mimic treated cells compared to NCs, this decrease was not statistically significant. Our results agree with Murphy et al's. (2016) demonstration of decreased Spred1 mRNA expression following miR-144 over-expression in primary cortical neurons. The authors also confirmed that Spred 1 is a direct downstream target of miR-144 [45], and these results strongly indicate that miR-144 regulates MAPK/ERK signalling by directly targeting its Spred1 suppressor. 


\section{Conclusion}

Our results document miR-144's oncogenic role in esophageal carcinogenesis by enhancing proliferation, migration and invasion of ESCC cells, and we confirmed that PURA is a direct downstream target for miR-144. Future challenges include identifying additional miR-144 targets which will further elucidate its function in esophageal carcinogenesis.

Acknowledgements: The authors thank the Department of Biotechnology; Ministry of Science and Technology; Government of India for funding this project (grant no. BT/PR13311/ GBD/27/246/2009) and Council of Scientific and Industrial Research (CSIR) for funding fellowship to Priyanka Sharma (grant no. 09/806(0021)/2011-EMR-I).

\section{References}

[1] FERLAY J, SOERJOMATARAM I, ERVIK M, FORMAN D, BRAY F et al. Globocan 2012: Estimated cancer incidence, mortality and prevalence in 2012. IARC 2018. http://globocan.iarc.fr

[2] PENNATHUR A, GIBSON MK, JOBE BA, LUKETICH JD. Oesophageal carcinoma. Lancet 2013; 381: 400-412. https:// doi.org/10.1016/S0140-6736(12)60643-6

[3] DI LEVA G, GAROFAlO M, CROCE CM. MicroRNAs in cancer. Annu Rev Pathol 2014; 9: 287-314. https://doi. org/10.1146/annurev-pathol-012513-104715

[4] FALK GW, SKACEL M, GRAMLICH TL, CASEY G, GOLDBLUM JR et al. Fluorescence in situ hybridization of cytologic specimens from Barrett's esophagus: a pilot feasibility study. Gastrointest Endosc 2004; 60: 280-284.

[5] CHEN YJ, KO JY, CHEN PJ, SHU CH, HSU MT et al. Chromosomal aberrations in nasopharyngeal carcinoma analyzed by comparative genomic hybridization. Genes Chromosomes Cancer 1999; 25: 169-175.

[6] ZHANG LY, HO-FUN LEE V, WONG AM, KWONG DL, ZHU YH et al. MicroRNA-144 promotes cell proliferation, migration and invasion in nasopharyngeal carcinoma through repression of PTEN. Carcinogenesis 2013; 34: 454463. https://doi.org/10.1093/carcin/bgs346

[7] WONG AM, KONG KL, TSANG JW, KWONG DL, GUAN XY. Profiling of Epstein-Barr virus-encoded microRNAs in nasopharyngeal carcinoma reveals potential biomarkers and oncomirs. Cancer 2012; 118: 698-710. https://doi. org/10.1002/cncr.26309

[8] SHARMA P, SARAYA A, SHARMA R. Potential diagnostic implications of miR-144 overexpression in human oesophageal cancer. Indian J Med Res 2016; 143: S91-S103. https:// doi.org/10.4103/0971-5916.191796

[9] XIE Z, CHEN G, ZHANG X, LI D, HUANG J et al. Salivary microRNAs as promising biomarkers for detection of esophageal cancer. PLoS One 2013; 8: e57502. https://doi. org/10.1371/journal.pone.0057502
[10] LI CY, LIANG GY, YAO WZ, SUI J, SHEN X et al. Identification and functional characterization of microRNAs reveal a potential role in gastric cancer progression. Clin Transl Oncol 2016; 19: 162-172. https://doi.org/10.1007/s12094-0161516-y

[11] GAEDCKE J, GRADE M, CAMPS J, SOKILDE R, KACZKOWSKI B et al. The rectal cancer microRNAome--microRNA expression in rectal cancer and matched normal mucosa. Clin Cancer Res 2012; 18: 4919-4930. https://doi. org/10.1158/1078-0432.CCR-12-0016

[12] WANG P, FU T, WANG X, ZHU W. [Primary, study of miRNA expression patterns in laryngeal carcinoma by microarray]. Lin Chung Er Bi Yan Hou Tou Jing Wai Ke Za Zhi 2010; 24: 535-538.

[13] IWAYA T, YOKOBORI T, NISHIDA N, KOGO R, SUDO T et al. Downregulation of miR-144 is associated with colorectal cancer progression via activation of mTOR signaling pathway. Carcinogenesis 2012; 33: 2391-2397. https://doi. org/10.1093/carcin/bgs288

[14] MACHOVA POLÁKOVA K, LOPOTOVA T, KLAMOVA $\mathrm{H}$, BURDA P, TRNENY $M$ et al. Expression patterns of microRNAs associated with CML phases and their disease related targets. Mol Cancer 2011; 10: 41. https://doi. org/10.1186/1476-4598-10-41

[15] AKIYOSHI S, FUKAGAWA T, UEO H, ISHIBASHI M, TAKAHASHI $Y$ et al. Clinical significance of miR-144-ZFX axis in disseminated tumour cells in bone marrow in gastric cancer cases. Br J Cancer 2012; 107: 1345-1353. https://doi. org/10.1038/bjc.2012.326

[16] NAMLØS HM, MEZA-ZEPEDA LA, BARØY T, ØSTENSEN IH, KRESSE SH et al. Modulation of the osteosarcoma expression phenotype by microRNAs. PLoS One 2012; 7: e48086. https://doi.org/10.1371/journal.pone.0048086

[17] CHENGAM, BYROMMW, SHELTONJ,FORD LP.Antisense inhibition of human miRNAs and indications for an involvement of miRNA in cell growth and apoptosis. Nucleic Acids Res 2005; 33: 1290-1297. https://doi.org/10.1093/nar/gki200

[18] OVCHARENKO D, KELNAR K, JOHNSON C, LENG N, BROWN D. Genome-scale microRNA and small interfering RNA screens identify small RNA modulators of TRAILinduced apoptosis pathway. Cancer Res 2007; 67: 10782 10788. https://doi.org/10.1158/0008-5472.CAN-07-1484

[19] LI J, YEN C, LIAW D, PODSYPANINA K, BOSE S et al. PTEN, a putative protein tyrosine phosphatase gene mutated in human brain, breast, and prostate cancer. Science 1997; 275: 1943-1947.

[20] SALMENA L, CARRACEDO A, PANDOLFI PP. Tenets of PTEN tumor suppression. Cell 2008; 133: 403-414. https:// doi.org/10.1016/j.cell.2008.04.013

[21] ZHU X, QIN X, FEI M, HOU W, GRESHOCK J et al. Loss and reduced expression of PTEN correlate with advancedstage gastric carcinoma. Exp Ther Med 2013; 5: 57-64. https://doi.org/10.3892/etm.2012.749

[22] WOODS K, ThOMSON JM, HAMMOND SM. Direct regulation of an oncogenic micro-RNA cluster by E2F transcription factors. J Biol Chem 2007; 282: 2130-2134. https://doi. org/10.1074/jbc.C600252200 
[23] PETROCCA F, VISONE R, ONELLI MR, SHAH MH, NICOLOSO MS et al. E2F1-regulated microRNAs impair TGFbeta-dependent cell-cycle arrest and apoptosis in gastric cancer. Cancer Cell 2008; 13: 272-286. https://doi. org/10.1016/j.ccr.2008.02.013

[24] LEE DY, JEYAPALAN Z, FANG L, YANG J, ZHANG Y, et al. Expression of versican 3'-untranslated region modulates endogenous microRNA functions. PLoS One 2010; 5: e13599. https://doi.org/10.1371/journal.pone.0013599

[25] SHARMA P, SAINI N, SHARMA R. miR-107 functions as a tumor suppressor in human esophageal squamous cell carcinoma and targets Cdc42. Oncol Rep 2017; 37: 3116-3127. https://doi.org/10.3892/or.2017.5546

[26] MANIKANDAN M, DEVA MAGENDHRA RAO AK, ARUNKUMAR G, MANICKAVASAGAM M, RAJKUMAR KS et al. Oral squamous cell carcinoma: microRNA expression profiling and integrative analyses for elucidation of tumourigenesis mechanism. Mol Cancer 2016; 15: 28. https:// doi.org/10.1186/s12943-016-0512-8

[27] WANG R, CHEN XF, SHU YQ. Prediction of non-small cell lung cancer metastasis-associated microRNAs using bioinformatics. Am J Cancer Res 2014; 5: 32-51.

[28] YU L, YANG Y, HOU J, ZHAI C, SONG Y et al. MicroRNA-144 affects radiotherapy sensitivity by promoting proliferation, migration and invasion of breast cancer cells. Oncol Rep 2015; 34: 1845-1852. https://doi.org/10.3892/ or. 2015.4173

[29] SUREBAN SM, MAY R, MONDALEK FG, QU D, PONNURANGAM $S$ et al. Nanoparticle-based delivery of siDCAMKL-1 increases microRNA-144 and inhibits colorectal cancer tumor growth via a Notch-1 dependent mechanism. J Nanobiotechnology 2011; 9: 40. https://doi. org/10.1186/1477-3155-9-40

[30] JIN J, WANG Y, XU Y, ZHOU X, LIU Y et al. MicroRNA-144 regulates cancer cell proliferation and cell-cycle transition in acute lymphoblastic leukemia through the interaction of FMN2.JGeneMed2017; 19.https://doi.org/10.1002/jgm.2898

[31] SUN L, BIAN G, MENG Z, DANG G, SHI D et al. MiR-144 Inhibits Uveal Melanoma Cell Proliferation and Invasion by Regulating c-Met Expression. PLoS One 2015; 10: e0124428. https://doi.org/10.1371/journal.pone.0124428

[32] HUO F, ZHANG C, HE H, WANG Y. MicroRNA-144-3p inhibits proliferation and induces apoptosis of human salivary adenoid carcinoma cells via targeting of mTOR. Biotechnol Lett 2016; 38: 409-416. https://doi.org/10.1007/s10529-0152007-x

[33] CAO T, LI H, HU Y, MA D, CAI X. miR-144 suppresses the proliferation and metastasis of hepatocellular carcinoma by targeting E2F3. Tumour Biol 2014; 35: 10759-10764. https:// doi.org/10.1007/s13277-014-2017-7

[34] CAI SD, CHEN JS, XI ZW, ZHANG LJ, NIU ML et al. MicroRNA 144 inhibits migration and proliferation in rectal cancer by downregulating ROCK 1 . Mol Med Rep 2015; 12 : 7396-7402. https://doi.org/10.3892/mmr.2015.4391
[35] JOHNSON EM, CHEN PL, KRACHMAROV CP, BARR SM, KANOVSKY $M$ et al. Association of human Pur alpha with the retinoblastoma protein, $\mathrm{Rb}$, regulates binding to the single-stranded DNA Pur alpha recognition element. J Biol Chem 1995; 270: 24352-24360.

[36] DARBINIAN N, GALLIA GL, KUNDU M, SHCHERBIK N, TRETIAKOVA A et al. Association of Pur alpha and E2F-1 suppresses transcriptional activity of E2F-1. Oncogene 1999; 18: 6398-6402. https://doi.org/10.1038/sj.onc.1203011

[37] DARBINIAN N, SAWAYA BE, KHALILI K, JAFFE N, WORTMAN B et al. Functional interaction between cyclin T1/cdk9 and Puralpha determines the level of TNFalpha promoter activation by Tat in glial cells. J Neuroimmunol 2001; 121: 3-11.

[38] LIU H, BARR SM, CHU C, KOHTZ DS, KINOSHITA Y et al. Functional interaction of Puralpha with the Cdk2 moiety of cyclin A/Cdk2. Biochem Biophys Res Commun 2005; 328: 851-857. https://doi.org/10.1016/j.bbrc.2005.01.038

[39] ULGER C, TORUNER GA, ALKAN M, MOHAMMED M, DAMANI $S$ et al. Comprehensive genome-wide comparison of DNA and RNA level scan using microarray technology for identification of candidate cancer-related genes in the HL-60 cell line. Cancer Genet Cytogenet 2003; 147: 28-35.

[40] BRUCHOVA H, BOROVANOVA T, KLAMOVA H, BRDICKA R. Gene expression profiling in chronic myeloid leukemia patients treated with hydroxyurea. Leuk Lymphoma 2002; 43: 1289-1295. https://doi.org/10.1080/10428190290026358

[41] INOUE T, LEMAN ES, YEATER DB, GETZENBERG RH. The potential role of purine-rich element binding protein (PUR) alpha as a novel treatment target for hormone-refractory prostate cancer. Prostate 2008; 68: 1048-1056. https:// doi.org/10.1002/pros.20764

[42] DARBINIAN N, GALLIA GL, KING J, DEL VALLE L, JOHNSON EM et al. Growth inhibition of glioblastoma cells by human Pur (alpha). J Cell Physiol 2001; 189: 334-340. https://doi.org/10.1002/jcp.10029

[43] STACEY DW, HITOMI M, KANOVSKY M, GAN L, JOHNSON EM. Cell cycle arrest and morphological alterations following microinjection of NIH3T3 cells with Pur alpha. Oncogene 1999; 18: 4254-4261. https://doi.org/10.1038/ sj.onc. 1202795

[44] WAKIOKA T, SASAKI A, KATO R, SHOUDA T, MATSUMOTO A et al. Spred is a Sprouty-related suppressor of Ras signalling. Nature 2001; 412: 647-651. https://doi. org/10.1038/35088082

[45] MURPHY CP, LI X, MAURER V, OBERHAUSER M, GSTIR $\mathrm{R}$ et al. MicroRNA-Mediated Rescue of Fear Extinction Memory by miR-144-3p in Extinction-Impaired Mice. Biol Psychiatry 2016; 81: 979-989. https://doi.org/10.1016/j.biopsych.2016.12.021 